\title{
Impact of Individual and Team Features of Patient Safety Climate: A Survey in Family Practices
}

Barbara Hoffmann, MD, MPH

Carolin Miessner, MPH

Zeycan Albay

Jakob Schröber

Katrin Weppler

Ferdinand M. Gerlach, MD, MPH

Corina Gütblin, $\mathrm{PbD}$

Institute of General Practice, Goethe University Frankfurt, Germany

\section{Conflicts of interest: authors report none.}

\section{CORRESPONDING AUTHOR}

Barbara Hoffmann, MD, MPH

Institute of General Practice

Goethe University

Theodor-Stern-Kai 7

D-60590 Frankfurt am Main

Germany

hoffmann@allgemeinmedizin.uni-frankfurt.de

\begin{abstract}
PURPOSE Knowledge about safety climate is fundamental to improving patient safety in health care organizations. Because individual and organizational factors influence the safety climate, we conducted a health care survey of German family practices so we could analyze the impact of the professional group, the professional experience of practice staff, and practice characteristics on perceptions of the safety climate.
\end{abstract}

METHODS We wrote to health care assistants and doctors in 1,800 randomly selected family practices in Germany and asked them to complete a newly developed and validated Frankfurt Patient Safety Climate Questionnaire. We conducted a descriptive analyses of items and climate factors, as well as regression analysis, to identify potential predictors of the safety climate in family practice.

RESULTS The response rate from the participating practices was $36.1 \%$. Safety climate was perceived to be generally positive with the exception of the factors of error management and perception of the causes of errors. We discovered that whether or not the entire team had taken part in the survey had a positive influence on most factors. Doctors had more positive perceptions of 4 of 7 factors addressed to both professions. Male participants and doctors showed the most willingness to admit they had made an error.

CONCLUSIONS Though the safety climate in German family practices was positive overall, health care professionals' use of incident reporting and a system's approach to errors was fairly rare. When evaluating the safety climate in primary health care practices, respondents' individual characteristics, as well as organizational features, should be taken into account.

Ann Fam Med. 2013;355-362. 10.1370/afm.1500.

\section{INTRODUCTION}

0 afety climate is perceived to be crucial to improving patient safety. Safety climate has been defined as "shared employee perceptions of the priority of safety... at their organization,"1 and it is assumed that the safety climate in an organization influences behavior by affecting the motivation and attitudes of health care professionals. ${ }^{2}$ Measuring safety climate is therefore the first step toward improving patient safety. Selfadministered questionnaires have been extensively used to evaluate the climate of an organization. ${ }^{3}$ Up to now very few studies of safety climate in primary care have been conducted ${ }_{i}$ however, recently instruments have been developed that help to assess the safety climate in this setting. ${ }^{4-8}$

Primary care organizations are often much smaller in terms of staff and diversity of professional groups than those found in secondary care. The most common type of office in primary care in Germany, ${ }^{9}$ as well as in Austria and France, remains the single-handed office, and in other countries like the United States ${ }_{,}^{10}$ Canada, ${ }_{1}^{11}$ and the Netherlands, ${ }^{12}$ considerable num- 
bers of single-handed practices also continue to exist. In Germany, teams in this setting consist of fewer than 10 professionals and are generally made up of 1 or 2 family physicians or general internists who are assisted by a team of 2 to 6 health care assistants. Health care assistants perform administrative and clerical work and carry out basic clinical procedures. Contrary to secondary care, primary health care focuses on chronic care and is characterized by long-term relationships with patients. Practices in Germany do not have lists of registered patients, and there is no gate-keeping system. Normally, offices are owned by the physicians.

Individual and organizational aspects have been shown to affect perceptions of the safety climate. For example, perceptions in the hospital sector are influenced by whether a person is a member of the frontline staff or holds a management position. ${ }^{13-17}$ Little is known, however, about whether the attributes of professionals and organizations influence the perceptions of safety in primary care and family practices in the same way. Considering the differences between primary and secondary care, results from the inpatient setting cannot be transferred to the primary sector.

We therefore conducted a survey of the patient safety climate in German family practices. The aim of the study was primarily to identify strengths and weaknesses of the safety climate in this setting, and secondarily to identify individual and practice features that affect the safety climate perceptions of health care professionals in primary care.

\section{METHODS}

\section{Participants}

We undertook a cross-sectional survey of family practices in Germany. Physicians are registered in all German states, but registered data are provided for study purposes in only one-half of them. We therefore used an electronic database of business addresses supplied by the national telephone company (yellow pages) to identify potential practices. Entering the search term "family practitioner" resulted in 31,826 hits. We used these hits as the basis for sampling. Before sampling, we had to merge the data sets (by the address and telephone number) to capture group practices that were not initially identified in the commercial database. The final database consisted of 31,052 practices.

\section{Sampling}

We took a stratified random sample of practices, with the strata being practice status (single-handed or group practice) and location defined in terms of community population size. Based on our experiences during a previous survey, we expected a response rate of about $37 \%$ of practices. ${ }^{6}$ Because $25 \%$ to $30 \%$ of family practices are estimated to be group practices, ${ }^{18}$ we calculated that we would need responses from at least 150 group practices to get a sufficiently large data set for multivariate analysis. We therefore chose to contact 1,800 practices $(150 \times 1 / 0.25 \%$ of group practices $\times 1 / 0.37$ response rate, plus an additional 180 practices as a safety margin).

Because there is no registry of health care assistants, we had to contact them through their practices. Inclusion criteria for practices were a minimum team size of 1 doctor and 1 health care assistant and the provision of health care to patients with statutory health insurance.

\section{The Survey}

The survey took place from April to June 2010. Two weeks after announcing the survey, we sent out letters of invitation, the questionnaires, and stamped reply envelopes to the practices. Every single-handed practice received 5 questionnaires, and every group practice 9 . As an incentive, we offered to provide the practices with feedback on the survey results. When necessary, we also sent up to 3 reminder letters at 2 weekly intervals, and we accompanied the second reminder with another set of questionnaires. The survey took place over a period of 8 weeks.

\section{The Instrument}

The Frankfurt Patient Safety Climate Questionnaire for General Practices (FraSiK) has been recently developed and validated in Germany. ${ }^{6}$ It consists of 44, 5-point Likert items with moderate to good internal consistency that circumscribe 9 factors. One factor is addressed only to doctors and 1 to only employees (Table 1). A further 25 items request information on emergency trainings, team sessions, etc, as well as other features regarding the handling of patient safety issues. Responses to these items were given either on a 5-point Likert scale, a dichotomous scale, or as free text. In addition to the questionnaire, we requested demographic information from the respondents (professional group, sex, age, professional experience in years, length of time in the current office, and working hours per week) and characteristics of the practice (practice status, team size).

\section{Data Management and Data Analysis}

Data entry was facilitated by the use of reading software (ReadSoft, ReadSoft AB), followed by several manual control steps. Items had to be reverse coded before analysis. The lower end of the scale (strongly disagree or never, depending on the content of the item) was coded as 1 and represented the most negative perception regarding safety climate, whereas the upper end (strongly agree or always) was coded as 5 and indi- 


\section{Table 1. Frankfurt Patient Safety Climate Questionnaire for General Practices (FraSiK) ${ }^{11}$}

\begin{tabular}{|c|c|c|c|}
\hline Factor & Content & No. of Items & Example of Item \\
\hline 1. Teamwork climate & $\begin{array}{l}\text { Collaboration, trust, respect, support, } \\
\text { openness, handling of conflicts, team } \\
\text { decision making }\end{array}$ & 12 & $\begin{array}{l}\text { It's easy for anyone in this practice to } \\
\text { ask questions if they don't understand } \\
\text { something. }\end{array}$ \\
\hline 2. Error management & $\begin{array}{l}\text { Handling of errors, reporting and } \\
\text { analysis }\end{array}$ & 6 & $\begin{array}{l}\text { Errors that occur in this practice are } \\
\text { discussed by the whole team. }\end{array}$ \\
\hline 3. Perception of causes of errors & $\begin{array}{l}\text { Causes of adverse events, recognition } \\
\text { of stress as negatively impacting } \\
\text { individual performance }\end{array}$ & 6 & $\begin{array}{l}\text { When errors occur in this practice, it } \\
\text { is because information has not been } \\
\text { properly relayed. }\end{array}$ \\
\hline 4. Safety of clinical processes & $\begin{array}{l}\text { Observing of rules, information } \\
\text { handling }\end{array}$ & 3 & $\begin{array}{l}\text { All information that is important for the } \\
\text { healthcare of patients is available to me. }\end{array}$ \\
\hline 5. Job satisfaction & Job and workplace satisfaction & 3 & This practice is a good place to work. \\
\hline 6. Safety of practice structure & $\begin{array}{l}\text { Maintenance of equipment, expiry dates } \\
\text { of drugs, overall priority of safety }\end{array}$ & 3 & $\begin{array}{l}\text { Medical equipment in this office is perfectly } \\
\text { suited to the care of our patients. }\end{array}$ \\
\hline $\begin{array}{l}\text { 7. Receptiveness to health care } \\
\text { assistants and patients }\end{array}$ & $\begin{array}{l}\text { Incorporation of suggestions from HCAs } \\
\text { and patients }\end{array}$ & 3 & $\begin{array}{l}\text { Patients' suggestions are given some } \\
\text { thought in this practice. }\end{array}$ \\
\hline $\begin{array}{l}\text { 8. Staff perception of } \\
\text { management (items addressed } \\
\text { only to employees) }\end{array}$ & $\begin{array}{l}\text { Feedback, fairness and openness of } \\
\text { discussions }\end{array}$ & 5 & $\begin{array}{l}\text { I receive constructive feedback on the } \\
\text { quality of my work. }\end{array}$ \\
\hline $\begin{array}{l}\text { 9. Quality and safety of medical } \\
\text { care (items addressed only to } \\
\text { doctors) }\end{array}$ & $\begin{array}{l}\text { Clinical guidelines, safe medication } \\
\text { handling }\end{array}$ & 3 & $\begin{array}{l}\text { Patients are asked about their current } \\
\text { medication when they come to see the } \\
\text { doctor. }\end{array}$ \\
\hline
\end{tabular}

HCA = health care assistant.

Note: Responses to items were generally given in a 5-point Likert scale format, ranging from strongly disagree to strongly agree or from never to always (with 1 representing the lower and 5 the upper end of the scales). The 25 items that were not part of the 9 scales had either 5 -point Likert or nominal scales, or free-text options.

cated the most positive perception. The intercepts of the scale $(2,3$, and 4$)$ were not verbally marked.

When participant responded to at least $75 \%$ of the Likert items relating to a specific factor, factor scores were calculated by calculating the mean response for these items. A mean of 4 or higher represents a positive safety climate. Free texts (eg, frequency of emergency training) were coded by us. Because the questionnaires had identification numbers, we were able to ascertain which questionnaires came from which practices. By using the information from the questionnaires on team size, we could also determine whether entire teams had participated in the survey.

All Likert scale data were treated as interval data. We decided to analyze the data on an individual level because this approach enables the effects of individual variables to be examined. Another reason for doing so concerns the ability to build aggregate measures on a unit level (such as percentage of positive or negative responses). When the sizes of units of aggregation vary (team sizes differed substantially from 2 to 253), aggregated values for small and large teams are difficult to compare, because only aggregated values from large practices can take the whole spectrum of potential values.

Taking potential predictors from literature into account, we examined the correlation matrix of these variables first. Variables were chosen when the correlation coefficient was lower than 0.4 , and multiple regression analyses of the safety climate factors were then carried out. The final set of variables included professional group ${ }^{13}$ (not applied to analyses of factors 8 and $9 ;$ Table 1), professional experience, ${ }^{19}$ team size, ${ }^{20}$ and location. ${ }^{21}$ Whether the entire team had participated was also added as an independent variable. In analyzing factor 9, we included age ${ }^{22}$ and $\operatorname{sex}^{23}$ because age and sex were more equally distributed in the group of physicians. In the analyses of factors 2 and 3 , we added the information about whether the respondent was aware of the national incidentreporting system, and whether she or he had admitted to having made errors in patient care ("I have made errors in patient care."), as we considered these to be important aspects of an individual's attitude toward patient safety. We used the stepwise inclusion of independent variables. Regression analyses were conducted with an $\alpha$ level of .0055 to account for multiple testing. Analyses were carried out using IBM SPSS Statistics 19 (International Business Machines Corp).

Participation in the survey was completely voluntary. Because this kind of study did not need to be reviewed by an ethics review board in Germany, no ethical approval was required based on a discussion of the issue with the institutional review board.

\section{RESULTS}

\section{Response Rate}

A small number of practices $(n=90)$ from the initial sample of 1,800 proved not to be eligible (because the practice did not exist anymore, or did not provide care 
to patients with German social, or statutory, health insurance). Of the 1,710 eligible practices, questionnaires from 618 practices were returned, resulting in a response rate of $36.1 \%$ on a practice level (Figure 1). In 171 cases, the entire team had participated. We received a total of 2,145 questionnaires from the 3,664 health care professionals that worked in the participating offices, representing a response rate of $58.5 \%$. The following analyses are based on 2,111 questionnaires that were appropriate for analysis (were completed and respondent met inclusion criteria).

\section{Individual and Practice Characteristics of the Sample}

Participants in the survey included 1,480 health care assistants, 599 doctors, and 32 persons whose professional group was not specified. Demographic data are displayed in Table 2. Most participants worked in single-handed practices (65.9\% of responding practices), group practices participated to a higher degree than single-handed practices when viewed in relation to the composition of the whole data set (Table 3 ) and compared with the expected share of $25 \%$ to $30 \% .^{18}$ because the item of reporting system for errors in use had been negatively scored by $53.9 \%$ of participants. The perception of causes of errors factor had a much wider range of responses with a mean of 2.81 (SD 0.73).

\section{Other Important Findings}

Of the items that were not associated with 1 of the 9 factors, $65.4 \%$ of respondents admitted to having made mistakes while caring for patients, and a few more (69.9\%) admitted that others in their practice had made mistakes in patient care. Patient safety is perceived to be something for which everyone in the practice feels responsible (mean score $=4.74, \mathrm{SD}=0.53$ ). Less than one-fifth, $16.1 \%$, of participants already knew the German patient safety incident-reporting system for family practices (www.jeder-fehler-zaehlt.de). ${ }^{24}$

Other results were more indirectly linked to patient safety but represent important features of quality and practice organization. Many, $72.1 \%$, participants stated that their practice had received complaints from patients in the past. More than $75 \%$ of those reporting the existence of complaints stated that the practices had reacted promptly to them. The majority of prac-

\section{Overall Perceptions of the Safety Climate}

For 7 of the 9 factors, the mean values were between 4.11 and 4.71 , showing a positive safety climate (Table 4). These factors were teamwork climate, safety of clinical processes, safety of practice structure, job satisfaction, receptiveness to health care assistants and patients, staff perception of management, and quality and safety of medical care. As an additional measure, we calculated the percentage of problematic responses by adding up the number of the responses at the lower end of the scales for each individual and factor (values 1 or 2 indicating negative perceptions of the safety climate) and dividing the sums by the total number of items attributable to the relevant factor. This percentage was generally low.

In contrast to these 7 factors, the results for 2 factors were somewhat different. The error management factor (mean score $=3.98, \mathrm{SD}=0.69)$ was perceived less positively, mainly

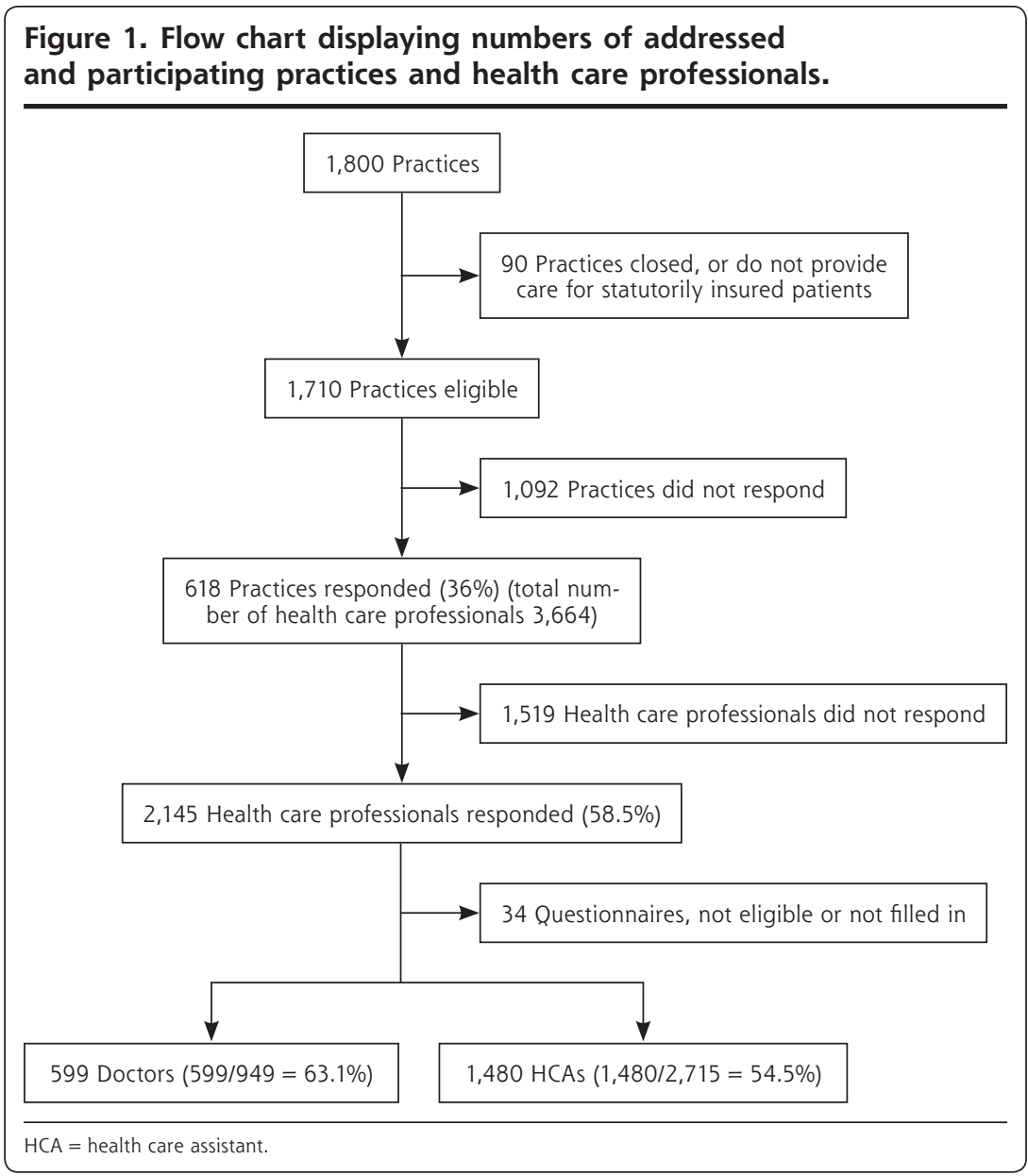


Table 2. Characteristics of Participating Health Care Assistants and Doctors

\begin{tabular}{lcc}
\hline & Health Care & \\
Participant Characteristic & Assistants & Doctors \\
\hline Number of participants & 1,480 & 599 \\
Response rate, \% & 54.51 & 63.12 \\
Female, \% & 98.3 & 42.7 \\
Age, No. (\%), Y & & \\
$\quad \leq 30$ & $452(30.5)$ & $2(0.3)$ \\
$31-40$ & $295(19.9)$ & $55(9.2)$ \\
$41-50$ & $448(30.3)$ & $177(29.5)$ \\
$51-60$ & $243(16.4)$ & $246(41.1)$ \\
$>60$ & $39(2.6)$ & $114(19.0)$ \\
Professional experience, No. (\%) & & \\
$<1$ year & $46(3.1)$ & $9(1.5)$ \\
$1-5$ years & $202(13.6)$ & $27(4.5)$ \\
$5-10$ years & $209(14.1)$ & $57(9.5)$ \\
$10-20$ years & $411(27.8)$ & $133(22.2)$ \\
$\geq 20$ years & $584(39.5)$ & $360(60.1)$ \\
Weekly working time, mean hr & 27.0 & 47.4 \\
\hline a There were 32 participants with missing data. & \\
\hline
\end{tabular}

Table 3. Characteristics of Participating Practices

\begin{tabular}{lcc}
\hline Characteristic & $\begin{array}{c}\text { Whole Sample } \\
(\mathbf{n}=\mathbf{1 , 8 0 0 )}\end{array}$ & $\begin{array}{c}\text { Participating } \\
\text { Practices } \\
(\mathbf{n}=\mathbf{6 1 8})\end{array}$ \\
\hline $\begin{array}{l}\text { Practice status, \% } \\
\text { Single-handed }\end{array}$ & 80 & \\
Group & 20 & 65.9 \\
Location, \% & & 33.2 \\
$\quad$ Rural town & 15.9 & \\
Small town & 28.6 & 18.8 \\
Medium-sized town & 26.8 & 30.7 \\
City & 28.6 & 25.6 \\
Team size, \% & & 24.9 \\
$\leq 4$ & Unknown & 38.8 \\
5-8 & Unknown & 43.7 \\
$>8$ & Unknown & 9.5 \\
\hline Note: Numbers do not add up to 100\% because of missing data.
\end{tabular}

tices undergo emergency training at least every third year $(81.7 \%)$. Nearly all practices hold team sessions at least quarterly (90.9\%).

\section{Predictors of the Safety Climate}

We found that health care assistants had a significantly more negative perception of 4 of the 7 factors addressed to both professional groups, ie, team work climate, error management, perception of causes of errors, and receptiveness to health care assistants and patients, and they had a more positive perception of the safety of clinical processes factor. Members of bigger practice teams had a significantly more negative perception of teamwork climate and safety of clinical processes. Having every team member responding to the questionnaire significantly predicted a positive safety climate for most factors.

Other independent variables predicted the value of only single factors (data not shown). All in all, correlations and the percentage of variation that was explained by the independent variables were generally low (between $1 \%$ and 12\%), with an explained variation of $5 \%$ and more for only 3 factors (error management, perception of causes of error, and teamwork climate.)

Regarding some of the individual items, we found responses were somewhat dependent on professional group and sex. More doctors than health care assistants admitted to having made a mistake in patient care $\left(89.9 \%\right.$ vs $\left.58.4 \% ; \chi^{2}=189.87, P=.000\right)$ and reported that mistakes had been made by other persons in the practice $\left(92.4 \%\right.$ vs $\left.65.4 \% ; \chi^{2}=155.73, P=.000\right)$. Differences by sex of the participant were analyzed only in the doctors' group because only $1.6 \%$ of the health care assistants in the sample were male. Significantly more male than female doctors admitted to having made a mistake $\left(92.8 \%\right.$ vs $\left.85.7 \% ; \chi^{2}=7.878, P=.005\right)$, whereas the difference in the level of admittance that others in the practice had made mistakes was not significant. More doctors than health care assistants were aware of the patient safety incident-reporting system for family practices $\left(37.2 \%\right.$ vs $\left.11.8 \% ; \chi^{2}=213.34, P=.000\right)$. Similarly, more doctors than health care assistants $(66.8 \%$ vs $59.2 \% ; \mathrm{n}=330$ aware of the system) had already used it (for reading reports or reporting incidents), but this difference was not significant $\left(\chi^{2}=1.96, P=.161\right)$.

\section{DISCUSSION}

This study shows that the safety climate in German family practices, as perceived by doctors and health care assistants, is generally positive. Nevertheless, results show areas for improvement, ie, in the perception of causes of errors factor and the reporting of patient safety incidents. Safety climate and other related aspects were generally influenced to a small degree by individual and practice team characteristics. The participation of the whole practice team had a consistent and generally positive influence on safety climate factors, whereas health care assistants had a more negative perception of 4 and members of larger practice teams of 2 of the factors. Doctors and male participants more often admitted that they or another person in the practice team had made a mistake in patient care.

\section{Safety Climate in Primary Care}

Safety climate has also been perceived as positive in other surveys of primary and ambulatory care. ${ }^{4,8,19,22,25}$ 
Although the survey instruments differed, and results are therefore not strictly comparable, this consistency is remarkable. Findings in the inpatient sector often show less-positive perceptions in general, and results differ greatly between hospitals and between hospital departments. ${ }^{13-15}$ One could argue, however, that this striking difference is an indication of a lower risk to patient safety in primary care or a lower risk perception by primary care professionals.

In our study, the factor perception of causes of error received the lowest scores. Responses at the lower end of this scale indicate that such causes as communication, organization, and stress are not recognized as contributing to errors in the respective practices and may indicate that most respondents did not take a systems approach to errors. ${ }^{26}$ One-half of the 6 items delineating this factor refer to the factor of stress recognition derived from the Safety Attitude Questionnaire, which also received the lowest values in 2 US studies. ${ }^{4,22}$ Some argue that because of a different response pattern, stress recognition has nothing to do with safety culture at all. ${ }^{27}$ One explanation may be that in contrast to most of the other items, the wording of these items refers to individual rather than group performance. Participants may therefore recognize the organization's perspective to a lesser degree and respond differently as a result.

Primary care in Germany is different from primary care in other countries in several respects. Office teams consist of only 2 different professional groups, compared with up to 8 in other primary care settings. ${ }^{19}$ In addition, team size is usually much smaller. Team size may have 2 implications: first, members of small teams may identify more strongly with their practice

Table 4. Scores for Patient Safety Climate Factors

\begin{tabular}{|c|c|c|c|c|c|}
\hline Factor & $\begin{array}{l}\text { Valid } \\
\text { Cases }\end{array}$ & $\begin{array}{l}\text { Mean } \\
\text { Score } \\
(\text { SD) }\end{array}$ & Range & $\begin{array}{l}\text { Percentage } \\
\text { Problematic } \\
\text { Response }^{b}\end{array}$ & $\begin{array}{c}\text { Missing } \\
\text { Values, } \\
\%\end{array}$ \\
\hline Safety of practice structure & 1,995 & $4.71(0.43)$ & $2-5$ & 0.6 & 5.5 \\
\hline Job satisfaction & 2,047 & $4.66(0.58)$ & $1-5$ & 1.5 & 3.03 \\
\hline Safety of clinical processes & 2,067 & $4.39(0.52)$ & $1.67-5$ & 1.1 & 2.08 \\
\hline Teamwork climate & 2,051 & $4.33(0.59)$ & $1.17-5$ & 3.4 & 2.84 \\
\hline $\begin{array}{l}\text { Quality and safety of } \\
\text { medical care }\end{array}$ & 596 & $4.19(0.56)$ & $2.33-5$ & 1.3 & 0.14 \\
\hline $\begin{array}{l}\text { Receptiveness to healthcare } \\
\text { assistants and patients }\end{array}$ & 2,013 & $4.11(0.62)$ & $1.33-5$ & 4.1 & 4.64 \\
\hline $\begin{array}{l}\text { Staff perception of } \\
\text { management }\end{array}$ & 1,487 & $4.11(0.79)$ & $1.2-5$ & 9.0 & 1.66 \\
\hline Error management & 2,090 & $3.98(0.69)$ & $1-5$ & 8.1 & 0.99 \\
\hline $\begin{array}{l}\text { Perception of causes or } \\
\text { errors }\end{array}$ & 2,029 & $2.81(0.73)$ & $1-5$ & 53.9 & 3.88 \\
\hline
\end{tabular}

and have a more positive perception of team climate in general, and doctors and nurses may work more closely together. ${ }^{22}$ The smaller team size may be a reason for the small though significant differences in perceptions between the professional groups in our study, as compared with findings in other surveys. $4,8,13,19$ Second, because relatively few individuals are involved in the day-to-day work and they are used to communicating flexibly, fewer than one-half of the respondents may have felt the need to use a patient safety incidentreporting system in their practice.

\section{Aspects That Affect Safety Climate Perceptions}

Individuals had a more positive perception of their safety climate when participation involved the entire practice team, which was the single variable almost consistently predicting a positive safety climate in our study. This finding may reflect that teams were more likely to take part in the study in their entirety if they worked in practices with a relatively good patient safety climate and may indicate response bias (see below). On the other hand, it may show that practice teams with a positive safety climate act more as a collective team than those with a less positive climate.

Some studies have claimed that membership of a particular professional group influences perceptions of safety climate in the inpatient as well as in the primary care setting, often with more doctors than nurses having positive perceptions of safety climate. ${ }^{14,15,22,27,28}$ Other research groups have found the opposite, however. ${ }^{4,29}$ We found health care assistants had less-positive perceptions for 4 of the 7 factors that applied to both professions. We have already cited a study in the inpatient setting which found that perceptions of frontline staff were less positive than those of management staff. This finding may indicate the experience of those on the front line differs from that of management because negative information does not always reach managers, thus leading to a different perspective. ${ }^{16}$ A Scottish study from primary care reported similar results, with the largest difference in safety climate perception occurring when respondents were grouped as management and employee, and attributed these findings to the "multi-faceted organizational role" of physicians in this setting. ${ }^{19}$ In Germany, nearly all family physicians are both frontline and management 
staff and may therefore have a more managerial perspective on safety and thus a more-positive perception of their safety climate. In our experience, physicians regard the practice's performance as predominantly their responsibility as doctors and employers, possibly explaining another finding in our study-physicians more often admitted having made errors in patient care.

In our study, a smaller team size predicted morepositive perceptions of the factors of teamwork climate and of safety of clinical processes compared with larger teams. Most recently, the US primary care database on safety culture applied the Medical Office Survey on Safety Culture to offices with 1 or 2 physicians and compared results with larger offices. The small offices had the most positive results on safety climate on all composites of the questionnaire, though the differences were small. ${ }^{25}$ A survey on organizational culture in health care studied the impact of team size and found a less cohesive and collegial culture in medical group practices of more than 10 physicians compared with smaller ones. ${ }^{20}$ It appears possible that a smaller, family-like office may lead to a stronger feeling of cohesion and team spirit, which in turn leads to a more positive safety climate.

\section{Strengths}

This survey is the first to measure safety climate in family practices in a German-speaking country, where practices typically represent microsystems with an intimate atmosphere. We applied a validated instrument recently developed for use in this particular setting. With regard to the number of health care professionals that participated, the overall response rate of $58.5 \%$ was satisfactory, with the response rate of doctors exceeding that of health care assistants $(63.1 \%$ vs $54.5 \%)$. This response rate is within the range of earlier studies summarized in a recent overview ${ }^{26}$ however, on a practice level the response rate is low but within the range of surveys in the same setting. ${ }^{19,30}$

\section{Limitations}

The low response rate could be the result of a voluntary response bias. Most practices that participated may already have been interested in the subject and therefore had a more positive perception of their safety climate. If so, it may also explain why some items and factors exhibited considerable ceiling effects, eg, job satisfaction and safety of practice structure. The percentage of group practices was higher in the participating group than in the whole sample of 1,710 eligible practices in our database $(33.2 \%$ vs $20.4 \%$ ), which may have also affected safety climate results.

Additionally, some of the analyzed individual and practice characteristics are moderately intercorrelated (eg, professional group and professional experience, as the professional training of physicians takes much longer than that of health care assistants and they usually start their professional career at an older age). Results should therefore be interpreted cautiously.

\section{Implications for Future Research and Clinical Practice}

We identified areas for improvement. Doctors and health care assistants should learn more about error causation and adopt a systems approach toward patient safety incidents, as a method to develop a memory for past errors and to learn from them appears to be less well developed in primary than in secondary care. ${ }^{31}$ Furthermore, health care assistants in particular should be motivated to contribute more to incident reporting and empowered to participate more actively in an open and fair safety culture.

In recent research a relationship between the safety climate and patient safety, as well as the reactivity of the climate resulting from safety improvement initiatives, has been shown in secondary care. ${ }^{32,33}$ To assess the current status and to help improve clinical governance, health care organizations in primary care are interested in safety culture measurement as well. ${ }^{34}$ When patient safety is addressed in a primary care context, the safety climate in family medicine is an important outcome measure for improvement initiatives.

In general, we found the participating practices' opinion of their safety climate to be positive or very positive with the exception of only 2 factors: error management and perception of causes or errors. Because measurement of a safety climate aims to detect areas of deficiencies to improve patient safety, the question still remains whether self-administered questionnaires are appropriate in this particular setting. Beyond that, the influence of the analyzed individual and practice characteristics on climate was low. The explained percentage of variance was highest, however, but still low for the domains error management and perception of causes or errors. Further research is needed to discover whether individual and office characteristics exert these small influences in other primary care settings as well, and whether other instruments (eg, the Manchester Patient Safety Framework ${ }^{35}$ ) for the evaluation of the safety climate are better suited to identifying strengths and weaknesses, as well as variations in the performance of different offices.

To read or post commentaries in response to this article, see it online at http://www.annfammed.org/content/11/4/355.

Key words: primary health care; family practice; safety climate; patient safety; health care survey

Submitted April 1, 2012; submitted, revised, July 16, 2012; accepted September 19, 2012. 
Contribution of authors: B. Hoffman was mainly responsible for the study design, with contributions from Z. Albay, C. Güthlin, and F.M. Gerlach. Z. Albay and B. Hoffman oversaw data collection, with contributions from K. Weppler, C. Miessner, and J. Schröber. B. Hoffman guided the analysis, with contributions from C. Güthlin, J. Schröber, and C. Miessner. All authors contributed to data interpretation and revisions to the manuscript, the first draft of which was prepared by B. Hoffman All authors had full access to the data derived from the study and can take full responsibility for the integrity of the data and the accuracy of the data analyses. B. Hoffman is guarantor for the study.

Funding support: This project was sponsored by a grant from the German Federal Ministry of Education and Research (project no. 01GK0702).

Acknowledgements We thank Phillip Elliott for his help and support with this article.

\section{References}

1. Zohar D, Livne Y, Tenne-Gazit O, Admi H, Donchin Y. Healthcare climate: a framework for measuring and improving patient safety. Crit Care Med. 2007;35(5):1312-1317.

2. Flin R. Measuring safety culture in healthcare: A case for accurate diagnosis. Saf Sci. 2007;45(6):653-667.

3. Halligan M, Zecevic A. Safety culture in healthcare: a review of concepts, dimensions, measures and progress. BMJ Qual Saf. 2011; 20(4):338-343.

4. Modak I, Sexton JB, Lux TR, Helmreich RL, Thomas EJ. Measuring safety culture in the ambulatory setting: the safety attitudes questionnaire-ambulatory version. J Gen Intern Med. 2007;22(1):1-5.

5. de Wet C, Spence W, Mash R, Johnson P, Bowie P. The development and psychometric evaluation of a safety climate measure for primary care. Qual Saf Health Care. 2010;19(6):578-584.

6. Hoffmann B, Domanska OM, Albay Z, et al. The Frankfurt Patient Safety Climate Questionnaire for General Practices (FraSiK): analysis of psychometric properties. BMJ Qual Saf. 2011;20(9):797-805.

7. Zwart DLM, Langelaan M, van de Vooren RC, et al. Patient safety culture measurement in general practice. Clinimetric properties of 'SCOPE'. BMC Fam Pract. 2011;12:117.

8. Agency for Healthcare Research and Quality (AHRQ). 2008 Prelimi nary Comparative Results: Medical Office Survey on Patient Safety Culture. hhttp://www.ahrq.gov/professionals/quality-patient-safety/ patientsafetyculture/medical-office/2008/mosurveyguide.pdf. Accessed Mar 4, 2012.

9. Schoen C, Osborn R, Huynh PT, Doly M. PEugh J, Zapert K. On the front lines of care: Primary care doctors' office systems, experiences and views seven countries in. Health Aff (Millwood). 2006;25(6):w555-w571.

10. Bodenheimer T, Pham HH. Primary care: current problems and proposed solutions. Health Aff (Millwood). 2010;29(5):799-805.

11. Canadian Medical Association. Pathway Evaluation Program and the Canadian Medical Residency Guide: Specialty Profile-Family Medicine. http://www.cma.ca/multimedia/CMA/Content_Images/ Inside_cma/Membership/profiles/Family-Practice_e.pdf.

12. van den Hombergh P. Saying 'goodbye' to single-handed practices; what do patients and staff lose or gain? Fam Pract. 2004;22(1):20-27.

13. Singer SJ, Gaba DM, Geppert JJ, Sinaiko AD, Howard SK, Park KC. The culture of safety: results of an organization-wide survey in 15 California hospitals. Qual Saf Health Care. 2003;12(2):112-118.

14. Kho ME, Carbone JM, Lucas J, Cook DJ. Safety Climate Survey: reliability of results from a multicenter ICU survey. Qual Saf Health Care. 2005:14(4):273-278.

15. Huang DT, Clermont G, Sexton JB, et al. Perceptions of safety culture vary across the intensive care units of a single institution. Crit Care Med. 2007;35(1):165-176.
16. Singer SJ, Falwell A, Gaba DM, Baker LC. Patient safety climate in US hospitals: variation by management level. Med Care. 2008; 46(11):1149-1156.

17. Carney BT, West P, Neily J, Mills PD, Bagian JP. The effect of facility complexity on perceptions of safety climate in the operating room: size matters. Am J Med Qual. 2010;25(6):457-461.

18. Kassenärztliche Bundesvereinigung. Struktur der Mitglieder in den Kassenärztlichen Vereinigungen zum 31.12.2010: Members of the regional associations of statutory health insurance physicians on 2010-12-31. http://daris.kbv.de/daris/doccontent.dll?LibraryName $=\mathrm{E}$ XTDARIS^DMSSLAVEESystemType $=2 \varepsilon$ Logonld $=$ e79eba89bd4fe 83 e830fb60c4fda47fe\&Docld $=003765078 \&$ Page $=1$.

19. de Wet C, Johnson P, Mash R, McConnachie A, Bowie P. Measuring perceptions of safety climate in primary care: a cross-sectional study. J Eval Clin Pract. 2012;18(1):135-142.

20. Curoe A, Kralewski J, Kaissi A. Assessing the cultures of medical group practices. J Am Board Fam Pract. 2003;16(5):394-398.

21. Singer SJ, Hartmann CW, Hanchate A, et al. Comparing safety climate between two populations of hospitals in the United States. Health Serv Res. 2009;44(5p1):1563-1583.

22. Holden LM, Watts DD, Hinton Walker P. Patient safety climate in primary care: age matters. J Patient Saf. 2009;5(1):23-28.

23. Carney BT, Mills PD, Bagian JP, Weeks WB. Sex differences in operating room care giver perceptions of patient safety: a pilot study from the Veterans Health Administration Medical Team Training Program. Qual Saf Health Care. 2010;19(2):128-131.

24. Hoffmann B, Beyer M, Rohe J, Gensichen J, Gerlach FM. "Every error counts": a web-based incident reporting and learning system for general practice. Qual Saf Health Care. 2008;17(4):307-312.

25. Agency for Healthcare Research and Quality (AHRQ). Medical Office Survey on Patient Safety Culture: 2012 User Comparative Database Report. http://www.ahrq.gov/professionals/quality-patientsafety/patientsafetyculture/medical-office/2012/index.html.

26. Reason J. Human error: models and management. BMJ. 2000;320 (7237):768-770.

27. Speroff T, Nwosu S, Greevy R, et al. Organisational culture: variation across hospitals and connection to patient safety climate. Qual Saf Health Care. 2010;19(6):592-596.

28. Singer $S$, Lin S, Falwell A, et al. Relationship of safety climate and safety performance in hospitals. Health Serv Res. 2009;44(2p1): 399-421.

29. Campbell EG, Singer S, Kitch BT, lezzoni LI, Meyer GS. Patient safety climate in hospitals: act locally on variation across units. Jt Comm J Qual Patient Saf. 2010;36(7):319-326.

30. Hummers-Pradier $E$, Scheidt-Nave C, Martin H, Heinemann $S$, Kochen MM, Himmel W. Simply no time? Barriers to GPs' participation in primary health care research. Fam Pract. 2008;25(2):105-112.

31. National Patient Safety Agency. NRLS Quarterly Data Workbook up to March 2011. http://www.nrls.npsa.nhs.uk/resources/collections/ quarterly-data-summaries/. Accessed Mar 4, 2012.

32. Mardon RE, Khanna K, Sorra J, Dyer N, Famolaro T. Exploring relationships between hospital patient safety culture and adverse events. J Patient Saf. 2010;6(4):226-232.

33. Haynes AB, Weiser TG, Berry WR, et al; Safe Surgery Saves Lives Study Group. Changes in safety attitude and relationship to decreased postoperative morbidity and mortality following implementation of a checklist-based surgical safety intervention. BMJ Qual Saf. 2011;20(1):102-107.

34. Mannion R, Konteh FH, Davies HTO. Assessing organisational culture for quality and safety improvement: a national survey of tools and tool use. Qual Saf Health Care. 2009;18(2):153-156.

35. Kirk S, Parker D, Claridge T, Esmail A, Marshall M. Patient safety culture in primary care: developing a theoretical framework for practical use. Qual Saf Health Care. 2007;16(4):313-320. 